\title{
Immediate Effect of Strong Surged Faradic Stimulation vs Self-Stretching in Less Tensed Position on Chronic Upper Trapezius Spasm in Young Females
}

\author{
Sharwari Shinde ${ }^{1}$, Rupali Shevalkar ${ }^{2}$ \\ ${ }^{1}$ B.P.Th., K. J. Somaiya College of Physiotherapy, Mumbai, India. \\ ${ }^{2}$ M.P.Th. in Musculoskeletal Sciences, Associate Professor, Department of Electrotherapy and Electrodiagnosis, \\ K. J. Somaiya College of Physiotherapy, Mumbai, India.
}

Corresponding Author: Sharwari Shinde

\begin{abstract}
Faulty postural habits lead to upper trapezius spasm causing pain and affection of neck mobility. The study aimed to compare the immediate effect of Strong Surged Faradic Stimulation and self-stretching in Less Tensed Position in chronic trapezius spasm in young females. 46 female subjects with unilateral chronic trapezius spasm between the age 18-25 years were randomly allocated into Strong Surged Faradic Stimulation group and self-stretching group. Pre and post intervention Numeric Pain Rating Scale and cervical lateral flexion range of motion was measured. Both the interventions were effective in reducing pain $(\mathrm{p}<0.0001)$ and improving range of motion $(\mathrm{p}<0.0001)$. When compared for pain, both were equally effective $(p=0.3664)$ but for range of motion self-stretching in Less Tensed Position was more effective $(\mathrm{p}<0.0001)$.
\end{abstract}

Keywords: Trapezius spasm, Strong Surged Faradic Stimulation, Self-Stretching, young females

\section{INTRODUCTION}

Young adults are prone to the development of musculoskeletal disorders as a result of their frequently attained improper postures while carrying out their activities of daily living. Neck pain being one of them. ${ }^{[1]}$ Neck pain is commonly observed in the posterior area of neck between the base of the neck to shoulder, indicating to the involvement of upper fibres of Trapezius muscle. ${ }^{[2-3]}$

The upper trapezius originates from medial $1 / 3^{\text {rd }}$ of superior nuchal line; external occipital protuberance; ligamentum nuchae; spinous processes of C7-T12 vertebrae corresponding to supraspinous ligaments and inserts into the posterior border of lateral $1 / 3^{\text {rd }}$ of clavicle. ${ }^{[4]}$ It is one of the prominent postural muscles subjected to overuse. Bad and awkward postures along with poor ergonomics over a prolonged period of time places the muscle in a tensed shortened position leading to the development of spasm. In addition, stressful thoughts and emotional stress along with abnormal breathing pattern result in excessive recruitment of upper Trapezius. ${ }^{[2]}$

These all components lead to significant restriction of cervical ranges along with tenderness and discomfort in the neck specifically in the posterolateral cervical region. ${ }^{[5-6]}$

A variety of Physiotherapy intervention like electro modalities, manual and exercise therapies are advocated and used for relief of pain and spasm. ${ }^{[7]}$

Strong Surged Faradic (SSF) Stimulation is a type of therapeutic 
electrical stimulation resulting in reduction of pain with improving joint range and mobility. ${ }^{[8]}$

Stretching is a general term used to describe any therapeutic manoeuvre designed to increase the extensibility of soft tissues, thereby improving flexibility and range of motion by elongating structures that have become hypomobile and have been adaptively shortened over time. ${ }^{[9]}$

The literature describes three techniques of muscle stretching namely Static, Dynamic and Pre-Contraction stretches. Among the three the most widely used is Static stretching, where a specific position is held with the muscle under tension to a point of stretching sensation and repeated. This technique can be performed either passively or actively. Active stretching is a technique that is performed by the subject himself (self-stretching). ${ }^{[10]}$

Active muscle stretching is preferred as it is safe, inexpensive, easy to perform and can be done as a regular selfadministered exercise. ${ }^{[11-12]}$ Active muscle stretching in a less tensed position (LTP) increases lateral flexion to the unaffected side. $^{[12]}$

Considering COVID-19 pandemic situation where Telerehabilitation has been gaining popularity, modes of treatment that can be incorporated as home program which are both comfortable and effective need to be researched into. Self-stretching technique is one of the techniques that can easily be self-administered by the patient at home whereas application of SSF Stimulation has to be done by the therapist demanding frequent visits to the clinics.

There is a lack of evidence comparing the efficacy of SSF Stimulation and self-stretching in LTP, hence this study is done to compare the immediate effects of the two interventions for helping the therapist in better clinical decision making.

\section{MATERIALS AND METHODS}

An approval from Institutional Review Board Committee for the study was taken. A comparative study with an experimental study design was conducted among 46 female ${ }^{[13]}$ students at K. J. Somaiya College of Physiotherapy over a period of 6 months.

Female students in the age group of 18-25 years of age having chronic (duration more than 3 months) ${ }^{[14]}$ unilateral upper trapezius spasm with tenderness and Numerical Pain Rating Scale score from 4 to 7 (including 4 and 7) were selected.

Individuals with history of cervical or shoulder injury, fracture and radiating pain to either of the upper extremities were excluded. Also, individuals with any pathological conditions like malignancy, any infection and cervical spondylosis were also excluded.

The subjects were explained about the study procedure and a written consent was taken from them. They were then randomly divided into two groups - Group 1 and Group 2 using computer generated randomized sampling method. Following the division into groups, they will first be assessed for pain using Numeric Pain Rating Sale and cervical range of motion (ROM) of lateral flexion using Universal Goniometer.

Numeric Pain Rating Scale (NPRS): It was used for recording pain intensity. ${ }^{[15-16]}$ The subjects were shown a 11-pointer scale ranging from 0 (no pain) to 10 (worst pain imaginable). ${ }^{[15]}$ The subjects were then asked to mark the pointer on the number that most accurately represents their level of perceived pain.

Universal Goniometer (UG): It was used for measuring cervical ranges of lateral flexion. ${ }^{[17][18]}$ For this the subject is in sitting position with the head in neutral position. The UG alignment is as follows:

- Fulcrum: Placed over the spinous process of C7 vertebra.

- Proximal arm: Aligned with the thoracic vertebrae spinous processes such that the arm is perpendicular to the ground. 
- Distal arm: Using the occipital protuberance as reference, it is aligned with the dorsal midline of the head.

The subject is instructed to try and touch ear to the shoulder but at the same time avoiding the head from moving forward, rotating or extending while performing the movement.

After the assessment was done, the subjects of Group 1 and Group 2 were given SSF Stimulation and self-stretching in LTP respectively.

Group 1 - The subjects of Group 1 received SSF Stimulation by muscle stimulator machine having Faradic current of symmetrical, Surged biphasic rectangular pulses of duration $0.1-1$ microsecond with a frequency of 50 Hertz for 90 contractions. $^{[19-20]}$ The electrodes for SSF Stimulation were placed on the Upper Trapezius muscle bulk (lateral to C7 spinous process and medial to the acromion).

Group 2 - The subjects of Group 2 were taught self-stretching in LTP, with the subject sitting upright on a chair and looking straight ahead; they then were asked to perform contralateral lateral flexion using the opposite hand on the frontal plane horizontally. ${ }^{[12]}$ Stretching position was maintained for a duration of $30 \mathrm{sec}$ and repeated three times.

Post the treatment both the groups were given 10 repetitions of neck range of motion exercises (flexion, extension, lateral flexion and rotations). ${ }^{[2]}$ At the end of the session, each subject was reassessed for immediate effect on pain and cervical ROM (lateral flexion).

\section{STATISCAL ANALYSIS}

Statistical analysis was done using Graph Pad Instat version 3 of the data collected from 46 subjects. The data that did not pass the normality test Wilcoxon matched pairs test and Mann-Whitney test was performed for intra and inter group whereas paired $t$ test was performed for the data passing the normality. Paired t test was done for pre post finding comparison for intra group. The inter group comparison was done by using unpaired $t$ test.

\section{RESULTS}

Table 1- Age Distribution
\begin{tabular}{|l|l|l|l|l|l|l|}
\hline Age & $\mathbf{2 0}$ & $\mathbf{2 1}$ & $\mathbf{2 2}$ & $\mathbf{2 3}$ & $\mathbf{2 4}$ & $\mathbf{2 5}$ \\
\hline Frequency & 2 & 3 & 18 & 15 & 6 & 2 \\
\hline
\end{tabular}

Table 2- Pain of Group 1 (SSF Stimulation)

\begin{tabular}{|l|l|l|l|}
\hline Pain & Mean & SD & 'p' value \\
\hline Pre & 5.739 & \pm 1.010 & $<0.0001$ (SIGNIFICANT) \\
\hline Post & 3.174 & \pm 1.669 & \\
\hline
\end{tabular}

Table 3- ROM of Group 1 (SSF Stimulation)

\begin{tabular}{|l|l|l|l|}
\hline ROM & Mean & SD & 'p' value \\
\hline Pre & 32.739 & \pm 2.800 & $<0.0001$ (SIGNIFICANT) \\
\hline Post & 36.043 & \pm 2.440 & \\
\hline
\end{tabular}

Table 4- Pain of Group 2 (Active stretching in LTP)

\begin{tabular}{|l|l|l|l|}
\hline Pain & Mean & SD & 'p' value \\
\hline Pre & 5.435 & \pm 1.080 & $<0.0001$ (SIGNIFICANT) \\
\hline Post & 3.217 & \pm 1.858 & \\
\hline
\end{tabular}

Table 5- ROM of Group 2 (Active Stretching in LTP)

\begin{tabular}{|l|l|l|l|l|}
\hline ROM & Mean & SD & $\begin{array}{l}\text { 't' } \\
\text { value }\end{array}$ & 'p' value \\
\hline Pre & 35.478 & \pm 4.795 & 10.822 & $\begin{array}{l}<0.0001 \\
\text { (SIGNIFICANT) }\end{array}$ \\
\hline Post & 39.739 & \pm 4.769 & & \\
\hline
\end{tabular}

Table 6- Comparison of pain between Group 1 and Group 2

\begin{tabular}{|l|l|l|l|}
\hline Pain & Mean & SD & 'p' value \\
\hline Group 1 & 2.565 & \pm 1.273 & 0.3664 (NOT SIGNIFICANT) \\
\hline Group 2 & 2.217 & \pm 1.204 & \\
\hline
\end{tabular}

Table 7- Comparison of ROM between Group 1 and Group 2

\begin{tabular}{|l|l|l|l|}
\hline ROM & Mean & SD & 'p' value \\
\hline Group 1 & 3.304 & \pm 0.8757 & $<0.0001$ (SIGNIFICANT) \\
\hline Group 2 & 4.261 & \pm 1.888 & \\
\hline
\end{tabular}

\section{DISCUSSION}

The purpose of this study was to assess and compare the immediate effect of Strong Surged Faradic (SSF) Stimulation and self-stretching in less tensed position (LTP) on pain and ROM in young females having upper trapezius spasm. The study was conducted among 46 young female adults between the age group of 18-25 years of age (Mean $=23 \pm 1$ ), who had unilateral trapezius spasm for a period of more than 3 months (chronic). The subjects were randomly divided into two groups - Group 1 and Group 2, who received SSF Stimulation and self-stretching in LTP respectively. NPRS for pain and Goniometer for measuring cervical lateral flexion ROM were used to evaluate pre-post effect of the intervention given. 
Our study observed that there was significant reduction in pain $(\mathrm{p}<0.0001)$ and increase in ROM ( $<<0.0001)$ among Group 1 participants treated with SSF Stimulation. This can be attributed as a result of- Electrical currents help in reducing the pain by assisting in the process of healing or by altering the transmission and perception of pain.

When a muscle contracts as a result of electrical stimulation, there is increased metabolism along with an increased demand for oxygen and foodstuffs also with a rise in the output production of metabolites. ${ }^{[22]}$ The metabolites lead to capillary and arteriolar dilatation causing a considerable increased blood flow to the muscle. ${ }^{[22]}$ This leads to removal of chemicals (metabolites) helping in reducing the level of nociceptive stimulation. ${ }^{[23]}$ A study done by Fusun Ardic et al ${ }^{[24]}$ concluded that Electrical Muscle Stimulation significantly improved pain in myofascial pain of upper trapezius muscle.

Electrical currents lessen the degree of muscle spasm by reducing the sensitivity of the muscle spindle system which eliminates the mechanical and chemical events stimulating transmission of pain. ${ }^{[21,25]}$ With the relief in muscle spasm, the ROM restricted increases. ${ }^{[26]}$ There was statistically significant improvement with Surged Faradic Stimulation in ROM on subjects having myofascial trigger points of trapezius in a study conducted by Akanksha A. Nalawade and Poonam H. Patil. ${ }^{[20]}$

The result of our study for SSF Stimulation intervention is in line with the result of the research conducted by Kshama S. Shetty and A. Joseph Oliver Raj [19] stating that Surged Faradic current has got beneficial effect in improving pain intensity and ROM on myofascial trigger point of upper trapezius.

The results of our study for selfstretching in LTP suggested significant reduction in pain $(\mathrm{p}<0.0001)$ and improvement in ROM ( $\mathrm{p}<0.0001)$.

Stretching causes firing of Golgi Tendon Organs which inhibits alpha motor neuron activity thereby causing musculotendinous unit relaxation by resetting its resting length and pacinian corpuscle modification. ${ }^{[27-28]}$ Kostopoulos et al ${ }^{[29]}$ found there was significant decrease in pain with passive stretching of upper trapezius, which is in accordance with this study.

Biochemical and thermal changes in the contractile and non-contractile structures of the muscle-tendon unit are the mechanisms responsible for gain in ROM. These gains are considered to be the result of increase in muscle extensibility and length or decreased muscle stiffness. ${ }^{[30]}$

Arja Hakkien ${ }^{[31]}$ reported significant improvement in pain and ROM by stretching in subjects with neck pain.

The results for the stretching group are supported by a study conducted by Kyue-Nam Park et al ${ }^{[12]}$ which concluded with a significant improvement in pre-post pain and ROM in patients with unilateral neck pain.

When inter group comparison was done it was found that both groups were equally effective in relieving pain ( $\mathrm{p}=$ 0.3664, insignificant). However, when compared for improvement in ROM, selfstretching in LTP seems to be significantly better ( $p<0.0001$, significant). This could be as stretching mainly focuses on increasing the length of a musculotendinous unit, essentially increasing the distance between origin and insertion of a muscle. ${ }^{[26]}$

Further research can be undertaken to investigate the long-term benefits of the interventions given on upper trapezius spasm as well as to analyse the effectiveness of the protocol as a part of Telerehabilitation program. Also, as the results of this study cannot be generalised to males, future research can be done on male population.

\section{CONCLUSION}

Thus, it can be concluded that both the interventions given are clinically beneficial in reducing pain and improving ROM and can be used in the management of 
patients with upper trapezius spasm. However, for improving ROM selfstretching in LTP was found to be more effective. In view of the ongoing pandemic, self-stretching itself can be used as an intervention for upper trapezius spasm as a home program for reducing pain and improving ROM.

\section{Acknowledgement: None}

\section{Conflict of Interest: None}

\section{Source of Funding: None}

\section{Ethical Approval: Approved}

\section{REFERENCES}

1. Sari M. Siivola. Neck and Shoulder pain in a young population: prevalence and etiological factors. Finland: University of Oulu Press; 2003. 71p.

2. Ekta S. Chaudhary, Nehal Shah, Neeta Vyas et al. Comparative Study of Myofascial Release and Cold Pack in Upper Trapezius Spasm. International Journal of Health Sciences \& Research. December 2013; 3(12):20-27.

3. Mikkel Brandt, Emil Sundstrup, Markus D. Jakobsen et al. Association between Neck/Shoulder Pain and Trapezius Muscle Tenderness in Office Workers. Pain Research and Treatment. March 2014; 2014: 352735.

4. Dr BD Chaurasia, Krishna Garg, Pragati Sheel Mittal, Mrudula Chandrupatla. BD Chaurasia's Human Anatomy Volume 1. 7th ed. India: CBS Publishers \& Distributors Pvt Ltd;2016. 65.

5. Shweta R. Rakholiya, Vaibhavi Ved. Effect of Ischemic Compression on Upper Trapezitis. International Journal of Current Advanced Research. July 2016; 5(7):11311134.

6. Dr Ashwini S. Bulbuli, Archana D. Methe. Immediate Effect of Spray and Stretch Technique on Trapezitis: An Experimental Study. Journal of Medical Science and Clinical Research. April 2017; 5(4):2059120596.

7. Daxa Mishra, R. Harihara Prakash, Jigar Mehta et al. Comparative Study of Active Release Technique and Myofascial Release
Technique in Treatment of Patients with Upper Trapezius Spasm. Journal of Clinical and Diagnostic Research. November 2018; 12(11): YC01-YC04.

8. William E. Prentice. Therapeutic Modalities for Physical Therapists. 2nd ed. United States of America: McGraw-Hill Professional; 2001. 73-74

9. Carolyn Kisner, Lynn Allen Colby. Therapeutic Exercise Foundations and Techniques. 6th ed. India: Jaypee Brothers Medical Publishers; 2012. 73.

10. Phil Page. Current Concepts in Muscle Stretching for Exercise and Rehabilitation. Int J Sports Phys Ther. Feb 2012; 7(1): 109119.

11. Jari Ylinen, Hannu Kautiainen, Kaija Wirén et al. Stretching exercises vs manual therapy in treatment of chronic neck pain: A randomized, controlled cross-over trial. Journal of rehabilitation medicine: official journal of the UEMS European Board of Physical and Rehabilitation Medicine. April 2007; 39: 126-32.

12. Kyue-Nam Park, Sung-min Ha, Si-Hyun Kim et al. Immediate Effects of Upper Trapezius Stretching in More and Less Tensed Positions on the Range of Neck Rotation in Patients with Unilateral Neck Pain. Physical Therapy Korea. February 2013; 20(1): 47-54.

13. Lindman R, Eriksson A, Thornell LE. Fibre type composition of the human female trapezius muscle: enzyme - histochemical characteristics. The American Journal of Anatomy. 1991; 190(4): 385-392.

14. Rolf-Detlef Treede, Winfried Rief, Antonia Barke et al. Chronic pain as a symptom or a disease: the IASP Classification of Chronic Pain for the International Classification of Diseases (ICD-11). PAIN. January 2019; 160(1): 19-27.

15. Breivik EK, Björnsson GA, Skovlund E. A Comparison of Pain Rating Scales by Sampling from Clinical Trail Data, The Clinical Journal of Pain. March 2000; 16(1): 22-28.

16. Ian A. Young, James Dunning, Raymond Butts. Reliability, construct validity, and responsiveness of the neck disability index and numeric pain rating scale in patients with mechanical neck pain without upper extremity symptoms. Physiotherapy Theory and Practice. December 2019; 35(12): 13281335. 
17. Muhammad Nazim Farooq, Mohammad A. Mohseni Bandpei, Mudassar Ali. Reliability of the universal goniometer for assessing active cervical range of motion in asymptomatic healthy persons. Pakistan Journal of Medical Sciences. March-April 2016; 32(2): 457-461.

18. Cynthia C. Norkin, D. Joyce White. Measurement of Joint Motion A Guide to Goniometry. 5th ed. United States of America: F. A. Davis Company; 2016. 434435.

19. Kshama. S. Shetty, A. Joseph Oliver Raj. Effect of Surged Faradic Current on Myofascial Trigger Point of Upper Trapezius Muscle as Compared with Manual Pressure Release. International Journal of Science and Research. March 2017; 6(3): 2304-2307.

20. Akanksha A. Nalawade, Poonam H. Patil. Comparison between Surged Faradic Current and Transcutaneous Electrical Stimulation (TENS) on Myofascial Trigger Points in Trapezius. Indian Journal of Physiotherapy and Occupational Therapy. January-March 2020; 14(1): 7-13.

21. Chad Starkey. Therapeutic Modalities. 4th ed. United States of America: F. A. Davis Company; 2013. 254.

22. Foster \& Palastanga. Clayton's Electrotherapy Theory \& Practice. 9th ed. India: A.I.T.B.S. Publishers \& Distributors; 2006. 63.

23. Foster \& Palastanga. Clayton's Electrotherapy Theory \& Practice. 9th ed. India: A.I.T.B.S. Publishers \& Distributors; 2006. 100-101.

24. Fusun Ardic, Merih Sarhus, Oya Topuz. Comparison of two different techniques of electrotherapy on myofascial pain. Journal of Back and Musculoskeletal Rehabilitation. January 2002; 16(1): 11-16.

25. Michelle H. Cameron. Physical Agents in Rehabilitation from Research to Practice. 2nd ed. United States of America: Saunders; 2003. 61.

26. Phil Page. Current Concepts in Muscle Stretching for Exercise and Rehabilitation. International Journal of Sports Physical Therapy. February 2012; 7(1): 109-119.

27. Carolyn Kisner, Lynn Allen Colby. Therapeutic Exercise Foundations and Techniques. 6th ed. India: Jaypee Brothers Medical Publishers; 2012. 81.

28. Walter R. Frontera. Rehabilitation of Sports Injuries: Scientific Basis. 1st ed. United Kingdom: Blackwell Science Ltd; 2003. 232-257.

29. Kostopoulos D, Nelson AJ, Ingber RS, Larkin RW. Reduction of spontaneous electrical activity and pain perception of trigger points in the upper trapezius muscle through trigger point compression and passive stretching. J Musculoskeletal Pain. 2008; 16: 266-278.

30. Carolyn Kisner, Lynn Allen Colby. Therapeutic Exercise Foundations and Techniques. 6th ed. India: Jaypee Brothers Medical Publishers; 2012. 76-77.

31. Hakkien A. Effect of manual therapy and stretching on neck muscle strength and mobility in chronic neck pain. Rehab Med. 2007; 39: 575-9.

How to cite this article: Shinde S, Shevalkar R. Immediate effect of strong surged faradic stimulation vs self-stretching in less tensed position on chronic upper trapezius spasm in young females. Int J Health Sci Res. 2021; 11(7): 345-350. DOI: https://doi.org/10.52403 /ijhsr.20210747 